\title{
The Comparision of Breast Cancer in the Young and Elderly Patients
}

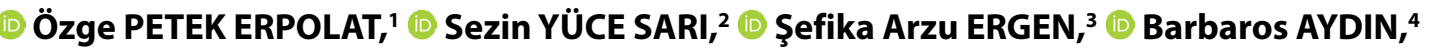 \\ (1) Berna AKKUŞ, ${ }^{5}$ (D) Melis GÜLTEKIN, ${ }^{2}$ (D) Didem ÇOPAN ÖKSÜZ, ${ }^{3}$ (D) Zümre ARICAN, ${ }^{4}$ (1) Cem ÖNAL, ${ }^{5}$

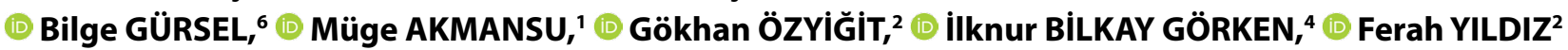

'Department of Radiation Oncology, Gazi University Faculty of Medicine, Ankara-Turkey

${ }^{2}$ Department of Radiation Oncology, Hacettepe University Faculty of Medicine, Ankara-Turkey

${ }^{3}$ Department of Radiation Oncology, İstanbul University Cerrahpaşa Faculty of Medicine, İstanbul-Turkey

${ }^{4}$ Department of Radiation Oncology, Dokuz Eylül University Faculty of Medicine, İzmir-Turkey

${ }^{5}$ Department of Radiation Oncology, Başkent University Faculty of Medicine Adana Dr. Turgut Noyan Research and Treatment Center Adana-Turkey

${ }^{6}$ Department of Radiation Oncology, Ondokuz Mayıs University Faculty of Medicine, Samsun-Turkey

\section{OBJECTIVE}

To compare the tumor characteristics, treatment approaches, recurrence patterns and survival results rates of young and elderly patients with breast cancer.

\section{METHODS}

In this study, Between between 2000-2013, a total of 779 patients were treated for breast cancer at nine radiation oncology departments were evaluated retrospectively. Three-hundred eight-four of these patients were young ( $\leq 35$ years), and 395 of those the patients were elderly ( $\geq 70$ years).

\section{RESULTS}

Young patients were more likely to present with aggressive tumor features. They were more often received comprehensive lymphatic irradiation, tumor bed boost and intense chemotherapy. No difference was found for 5 and 10 -year loco-regional recurrence- free survival rates were (96\% and $93 \%$ for young, $97 \%$ and $97 \%$ for elderly). The 5 and 10-year distant recurrence- free survival rates were lower in the young patients (77\% and $67 \%$ for young, $85 \%$ and $85 \%$ for elderly, $\mathrm{p}<0.0001$ ). No difference was found in 5 and 10 -year breast cancer- specific survival ( $91 \%$ and $79 \%$ for young, $92 \%$ and $87 \%$ for elderly). The 5 and 10 -year overall survival rates were higher in the young patients ( $92 \%$ and $78 \%$ for young, $78 \%$ and $63 \%$ for elderly, $\mathrm{p}<0.0001$ ).

\section{CONCLUSION}

The reason for the similarity between the age groups in terms ofregarding loco-regional recurrence- free survival can be more comprehensive lymphatic irradiation and tumor bed boost, the young patients received. The distant recurrence- free survival rates rates were significantly lower in the young patients even though they received more intensive chemotherapy. Future studies aimed at more effective systemic regimens to decrease distant recurrence in young patients are warranted.

Keywords: Breast cancer; distant metastasis; elderly patients; loco-regional relapse; young age. Copyright $\odot$ 2019, Turkish Society for Radiation Oncology

\section{Introduction}

Breast cancer (BC) is the most common malignancy in women worldwide. Despite a decrease in BC specific mortality, it is one of the leading causes of cancer death among women. [1] Age is a dominant risk factor in the development of BC. According to the SEER database, the median age at the time of $\mathrm{BC}$ diagnosis is 62 years.
Received: June 14, 2019

Accepted: July 22, 2019

Online: August 27, 2019

Accessible online at:

www.onkder.org

OPEN ACCESS This work is licensed under a Creative Commons

Attribution-NonCommercial 4.0 International License.
Dr. Özge PETEK ERPOLAT,

Gazi Üniversitesi Tıp Fakültesi,

Radyasyon Onkolojisi,

Ankara-Turkey

E-mail: petektater@yahoo.com 
[2] Approximately less than $4 \%$ of women diagnosed with BC are younger than 35 years. [3] Definition of young age in $\mathrm{BC}$ has been controversial; in some studies, the cut-off points at different years have been identified according to the poor survival status compared to older counterparts. In many series, patients at 35 year or younger showed poor prognosis and increased risk of local-regional recurrence (LRR) and distant recurrence (DR). [4,5] This could partly be explained by BC at a young age is associated with more advanced stage and more biologically aggressive disease.[6-9] These aggressive biological features of $\mathrm{BC}$ in young patients include higher grade, higher proliferation rate, more lymphovascular invasion (LVI), more absence of hormone receptors, and higher prevalence of human epidermal factor receptor-2 (HER2) positive or triple negative disease. $[5,7,8,10-12]$ It is controversial whether these adverse prognostic factors mainly explain the poor outcome of young patients or the young age all by itself has an adverse prognostic significance. $[13,14]$ On the other hand, since young age in $\mathrm{BC}$ is generally thought to be an adverse prognostic factor, these patients receive more aggressive treatments than elderly patients. [8,15]

One-third of all BCs occur in patients aged over 70 years.[16] BC in elderly patients has been reported relatively indolent in despite of the younger counterparts in several studies.[17] The biological characteristics of their tumors are more favorable. They represent higher estrogen receptor (ER) and progesterone receptor (PR) expression, less LVI, less HER2 expression, and lower proliferative rates.[18-21] Nonetheless, some studies suggest that older women generally have poor prognosis. [22,23] This is mostly explained by delayed diagnosis or lack of routine mammographic screening.[23] Moreover, the co-morbidities of elderly patients often limit therapeutic options and patients' compliance.[24] They receive less aggressive surgery and less frequent use of radiotherapy and chemotherapy even in patients with good performance status. $[9,25,26]$

Since two distinct age spectrum of women are underrepresented in the clinical trials, the exact reasons for poor outcomes remain unclear. Few studies have assessed whether very young or elderly patients have different patterns of LRR and DR. It is speculated that young patients receive more intensive therapy; therefore, they might have better survival after LRR or DM, despite a shorter disease-free survival.[27] This study aimed to evaluate the pathological characteristics, treatment approaches, recurrence patterns, and survival outcomes of very young and elderly patients.

\section{Materials and Methods}

The patients treated for $\mathrm{BC}$ in nine Radiation Oncology Departments between 2000 and 2013 were retrospectively reviewed. The inclusion criteria were patients $\leq 35$ years old and $\geq 70$ years old and patients with invasive $\mathrm{BC}$ who received radiotherapy after breast-conserving surgery or mastectomy. The exclusion criteria were stage IV disease, bilateral BC, male gender, patients aged between 36 and 69 years, and patients with other malignancies except basal cell carcinoma of the skin and carcinoma in situ of cervix. The local ethics committee approved the study, and informed consent was obtained from the patients.

Patients' medical history, co-morbidities, family history, tumor features, staging, initial treatment, and clinical outcomes were obtained from hospital databases. Pathological assessment included the evaluation of primary tumor size, histological type, tumor grade, LVI, perineural invasion (PNI), surgical margin, lymph node status, extranodal extension, ER, PR, HER2 expression, and Ki-67 labeling index status. Tumor staging was performed according to 2002 American Joint Committee on Cancer guidelines.[27] The status of ER, PR, and HER2 were determined by immunohistochemistry. ER or PR positivity was determined if at least $1 \%$ of the tumor cells had positive nuclear staining. Hormone receptor positivity was defined as $\mathrm{ER}(+) /$ $\mathrm{PR}(+), \operatorname{ER}(+) / \mathrm{PR}(-)$ or $\mathrm{ER}(-) / \mathrm{PR}(+)$. HER2 positivity was defined as an immunohistochemical score of $3+$ or $2+$ with positive gene amplification by using fluorescent in situ hybridization or chromogenic in situ hybridization.

The last date of follow-up and the date of first recurrences or death were recorded. End points were calculated as the interval between definitive surgery and event of the interest. We evaluated the recurrence patterns, the 5- and 10-year locoregional recurrencefree survival (LRFS), distant recurrence-free survival, breast cancer specific survival (BCSS), and overall survival (OS). LRR was defined as the first relapse in the ipsilateral breast, chest wall, or overlying skin and nodal regions. The contralateral BC was considered as new event. Any other site of recurrence was defined as DR. LRFS was defined as time from definitive surgery to any locoregional recurrence or last follow-up/death. DRFS was defined as time from definitive surgery to any DR or last follow-up/death. BCSS was defined as time from definitive surgery to death from $B C$ or last follow-up/death. OS was defined as time from surgery to death from any causes or last follow-up/death. 


\section{Statistical Analysis}

All analyses were performed using the SPSS software, version 20 (SPSS Inc, Chicago, IL). The patients were categorized by age into two groups. Descriptive statistics were generated for all variables and were summarized with frequencies and percentages. The significance of differences in categorical variables such as patient and tumor characteristics, treatment features, and recurrence patterns were compared across age groups using Pearson's chi-squared or Fischer exact test if necessary. Survival and recurrence data were analyzed using the Kaplan-Meier estimated method, and the survival/ recurrence curves were compared using the log-rank test. Multivariate analyses were conducted using Cox's proportional hazard regression modeling. The value of $\mathrm{p} \leq 0.05$ was considered as statistically significant.

\section{Results}

\section{Patient Characteristics}

A total of 779 patients who were treated in nine centers were evaluated. Among them, $49 \%$ of patients $(n=384)$ were young and $51 \%$ of patients $(n=395)$ were elder. The median age of young and elder patients was 30 (19-35) and 74 (70-87) years, respectively. The co-morbidities were higher in the elderly ( $10 \%$ vs. $62 \%, \mathrm{p}<0.001)$. The number of patients who had family history of $\mathrm{BC}$ was higher in the young patients ( $21 \%$ vs. $12 \%, \mathrm{p}=0.002$ ).

The young patients presented with higher incidence of clinical stage II and III ( $79 \%$ vs. $70 \%, \mathrm{p}=0.011$ ), grade 3 tumors ( $48 \%$ vs. $30 \%, \mathrm{p}<0.0001$ ), positive lymphovascular space invasion (LVI) ( $64 \%$ vs. $51 \%, \mathrm{p}<0.001), \geq 15 \%$ $\mathrm{Ki}-67$ status ( $86 \%$ vs. $51.5 \%, \mathrm{p}<0.002)$, negative hormone receptor (ER/PR) ( $27 \%$ vs. $15 \%, \mathrm{p}<0.0001)$, positive c-erb-B2 ( $34 \%$ vs. $26 \%, \mathrm{p}=0.015)$, and triple negative subtype ( $18 \%$ vs. $8 \%, \mathrm{p}<0.001$ ). No difference was found between the groups regarding pathologic tumor stage, pathologic PNI, histopathological subtypes, and surgical margins. The clinical and pathological characterizations of the patients are summarized in Table 1.

Young patients had more breast-conserving surgeries $(42 \%$ vs. $34 \%, \mathrm{p}=0.02)$ and axillary dissection after positive sentinel lymph node biopsy (20\% vs. $7 \%, \mathrm{p}=0.0001)$. The percentage of young patients who receive chemotherapy was also higher $(96 \%$ vs. $66 \%$, $\mathrm{p}=0.0001)$. Although young patients were more likely to be treated with neoadjuvant chemotherapy ( $22 \%$ vs. $13 \%)$, elderly patients were more likely to be treated with adjuvant chemotherapy ( $78 \%$ vs. $87 \%, p=0.0001$ ). Young patients were more likely to receive doxorubicin, taxane, and doxorubicin + taxane chemotherapy regimens $(p<0.0001)$. The number of patients who receive hormone-therapy was higher in elderly $(\mathrm{p}=0.012)$, while no difference was found between two groups in terms of anti-HER2 treatment. All patients in this retrospective study received adjuvant radiotherapy after mastectomy or breast-conserving surgery. The rate of application only tangential fields to breast or chest wall alone was found similar between the groups (30\% vs. $30 \%)$. The comprehensive lymphatic irradiation (included axilla, supraclavicular fossa, internal mammary lymph nodes) ratio was found higher in young patients ( $29 \%$ vs. $15 \%$; $=0.0001)$. In addition, young patients had more likely received boost ( $49 \%$ vs. $28 \%$, $\mathrm{p}=0.0001$ ). No difference was found in terms of median RT dose to the breast or chest wall and boost dose across the two patient groups $(p=0.0001)$. The treatment features of the patients are shown in Table 2.

\section{Survival Analysis}

The median follow-up time for young and elderly patients was 67.5 (5-193) months and 54 (5-188) months, respectively. The 5- and 10-year LRFS rates were 96\% and $93 \%$ for young patients and $97 \%$ and $97 \%$ for elderly patients $(\mathrm{p}=0.211)$ (Figure 1a). The 5- and 10year DRFS rates were $77 \%$ and $67 \%$ for young patients and $85 \%$ and $85 \%$ for elderly patients $(\mathrm{p}<0.0001)$ (Figure $1 \mathrm{~b}$ ). The 5 - and 10 -year BCSS rates were $91 \%$ and $79 \%$ for young patients, and $92 \%$ and $87 \%$ for elderly. Although the difference in 10 -year BCSS rate was $8 \%$ between the groups, it did not reach a statistical significance $(\mathrm{p}=0.243)$ (Figure 1c). The 5- and 10-year OS rates were $92 \%$ and $78 \%$ for young patients and $78 \%$ and $63 \%$ for elderly ( $\mathrm{p}=0.0001$ ) (Figure $1 \mathrm{~d}$ ).

Based on multivariate survival analysis, age was the significant prognostic factor for DRFS and OS. In addition to younger age, higher pathologic tumor stage and positive pathologic lymph node were negatively related to DRFS. Higher pathologic tumor stage and tumor grade and presence of lymphovascular space invasion were negatively related to LRFS. Higher clinical and pathological tumor stage, positive pathological lymph node, and higher tumor grade were found as significant negative prognostic factors on BCSS. Elder age, higher clinical stage, and tumor grade were negative prognostic factors on OS. The multivariate survival analysis results are shown in Table 3.

\section{Recurrence Patterns}

At the last follow-up, 98 (26\%) patients in young patients had recurrences. Most common recurrence pattern was DM (86\%). Fourteen of the young patients (5\%) developed contralateral BC. At the last follow-up, $55(15 \%)$ patients died from BC, and 4 (1\%) patients died from other causes not related to BC. In the elderly, 
Table 1 The clinical and pathological characterizations of the patients

\begin{tabular}{|c|c|c|c|}
\hline & Young women n, (\%) & Elderly women n, (\%) & $\mathbf{p}$ \\
\hline Median age & $30(19-35)$ & $74(70-87)$ & - \\
\hline \multicolumn{4}{|l|}{ Co-morbidity } \\
\hline Negative & 335 (90\%) & $139(38 \%)$ & \multirow[t]{2}{*}{0.0001} \\
\hline Positive & $36(10 \%)$ & $228(62 \%)$ & \\
\hline \multicolumn{4}{|l|}{ Family history } \\
\hline Negative & 290 (79\%) & $318(88 \%)$ & \multirow[t]{2}{*}{0.002} \\
\hline Positive & $76(21 \%)$ & $45(12 \%)$ & \\
\hline \multicolumn{4}{|l|}{ Clinical stage } \\
\hline $0-1$ & $72(21 \%)$ & $92(30 \%)$ & \multirow[t]{2}{*}{0.011} \\
\hline $2-3$ & 272 (79\%) & 219 (70\%) & \\
\hline \multicolumn{4}{|l|}{ Histopathology } \\
\hline Invasive lobular carcinoma & $36(9.5 \%)$ & $24(6 \%)$ & \multirow[t]{4}{*}{0.214} \\
\hline Invasive ductal carcinoma & $272(71 \%)$ & $302(77 \%)$ & \\
\hline Invasive lobular+ductal carcinoma & $32(8.5 \%)$ & $29(7 \%)$ & \\
\hline Others & $43(11 \%)$ & $39(10 \%)$ & \\
\hline \multicolumn{4}{|l|}{ Pathologic tumor stage } \\
\hline $0-2$ & 301 (79\%) & $316(80 \%)$ & \multirow[t]{2}{*}{0.531} \\
\hline $3-4$ & $82(21 \%)$ & $77(20 \%)$ & \\
\hline \multicolumn{4}{|l|}{ Pathologic node status } \\
\hline NO & $119(31 \%)$ & $122(32 \%)$ & \multirow[t]{2}{*}{0.854} \\
\hline N1-3 & 265 (69\%) & $264(68 \%)$ & \\
\hline \multicolumn{4}{|l|}{ Tumor grade } \\
\hline 1 & $21(6 \%)$ & $53(15 \%)$ & \multirow[t]{3}{*}{0.0001} \\
\hline 2 & $173(47 \%)$ & $202(56 \%)$ & \\
\hline 3 & $176(48 \%)$ & $109(30 \%)$ & \\
\hline \multicolumn{4}{|l|}{ Surgical margin } \\
\hline Negative & 347 (91\%) & 364 (93\%) & \multirow[t]{3}{*}{0.332} \\
\hline Positive & $14(4 \%)$ & $8(2 \%)$ & \\
\hline Close ( $\leq 2 \mathrm{~mm})$ & $21(5 \%)$ & $18(5 \%)$ & \\
\hline \multicolumn{4}{|l|}{ Lymphovascular invasion } \\
\hline Negative & $122(36 \%)$ & $151(49 \%)$ & \multirow[t]{2}{*}{0.001} \\
\hline Positive & $214(64 \%)$ & $155(51 \%)$ & \\
\hline \multicolumn{4}{|l|}{ Perineural invasion } \\
\hline Negative & $203(75 \%)$ & $174(69 \%)$ & \multirow{2}{*}{0.184} \\
\hline Positive & $67(25 \%)$ & 77 (31\%) & \\
\hline \multicolumn{4}{|l|}{ Ki 67 proliferation (\%) } \\
\hline$<15$ & $6(14 \%)$ & $16(48.5 \%)$ & 0.001 \\
\hline$\geq 15$ & $36(86 \%)$ & $17(51.5 \%)$ & \\
\hline Hormone receptor status & & & \\
\hline Negative & $103(27 \%)$ & $58(15 \%)$ & 0.0001 \\
\hline Positive & $274(73 \%)$ & 329 (85\%) & \\
\hline HER2 status & & & \\
\hline Negative & $240(66 \%)$ & $263(74 \%)$ & 0.01 \\
\hline Positive & 125 (34\%) & $91(26 \%)$ & \\
\hline Triple negative tumor & & & \\
\hline Negative & 300 (82\%) & 324 (92\%) & 0.0001 \\
\hline Positive & $64(18 \%)$ & $29(8 \%)$ & \\
\hline Tumor grade & & & \\
\hline 1 & $21(6 \%)$ & 53 (15\%) & 0.0001 \\
\hline 2 & $173(47 \%)$ & 202 (56\%) & \\
\hline 3 & $176(48 \%)$ & $109(30 \%)$ & \\
\hline
\end{tabular}

SLNB: Sentinel lymph node biopsy 
Table 2 The treatment features of the patients

\begin{tabular}{|c|c|c|c|}
\hline & Young women n, (\%) & Elderly women $\mathrm{n},(\%)$ & $\mathbf{p}$ \\
\hline \multicolumn{4}{|l|}{ Surgery } \\
\hline Breast conserving surgery & $160(42 \%)$ & $134(34 \%)$ & 0.02 \\
\hline Mastectomy & $224(58 \%)$ & $261(66 \%)$ & \\
\hline \multicolumn{4}{|l|}{ Axillary surgery } \\
\hline None & $2(0.5 \%)$ & $15(4 \%)$ & 0.0001 \\
\hline SLNB & $46(12 \%)$ & $48(12 \%)$ & \\
\hline SLNB and axillary dissection & $75(20 \%)$ & $27(7 \%)$ & \\
\hline Axillary dissection & $260(67.5 \%)$ & $304(77 \%)$ & \\
\hline \multicolumn{4}{|l|}{ Chemotherapy } \\
\hline No & $14(4 \%)$ & $128(34 \%)$ & 0.0001 \\
\hline Yes & $367(96 \%)$ & $250(66 \%)$ & \\
\hline \multicolumn{4}{|l|}{ Chemotherapy } \\
\hline Neoadjuvant & $80(22 \%)$ & $32(13 \%)$ & 0.0001 \\
\hline Adjuvant & $287(78 \%)$ & $218(87 \%)$ & \\
\hline \multicolumn{4}{|l|}{ Type of initial chemotherapy } \\
\hline Doxorubicin containing regimen & $68(21 \%)$ & $42(20 \%)$ & 0.0001 \\
\hline Taxane containing regimen & $59(18 \%)$ & $44(21 \%)$ & \\
\hline Doxorubicin+Taxane containing regimen & $113(35 \%)$ & $42(20 \%)$ & \\
\hline Other regimens & $83(26 \%)$ & $84(39 \%)$ & \\
\hline \multicolumn{4}{|l|}{ Hormonal therapy } \\
\hline Negative & $110(33 \%)$ & $65(23 \%)$ & 0.012 \\
\hline Positive & $226(67 \%)$ & $214(77 \%)$ & \\
\hline \multicolumn{4}{|l|}{ Anti-HER2 therapy } \\
\hline Negative & 295 (82\%) & 265 (84\%) & 0.512 \\
\hline Positive & $63(18 \%)$ & $49(16 \%)$ & \\
\hline \multicolumn{4}{|l|}{ Radiotherapy fields } \\
\hline Tangential & $114(30 \%)$ & $117(30 \%)$ & 0.0001 \\
\hline Tangential+axilla+supra & $160(42 \%)$ & $217(55 \%)$ & \\
\hline Tangential+axilla+supra+MI & $110(29 \%)$ & $61(15 \%)$ & \\
\hline \multicolumn{4}{|l|}{ Boost } \\
\hline Negative & $197(51 \%)$ & $285(72 \%)$ & 0.0001 \\
\hline Positive & $187(49 \%)$ & $110(28 \%)$ & \\
\hline \multicolumn{4}{|l|}{ Radiotherapy dose (median) } \\
\hline Breast/chestwall dose & 50 Gy (45-50.4) & 50 Gy (45-50.4) & 0.834 \\
\hline Boost dose & 10 Gy $(8-20)$ & 10 Gy (6-16) & 0.128 \\
\hline
\end{tabular}

SLNB: Sentinel lymph node biopsy; MI: Mammaria interna

$46(13 \%)$ patients had recurrences. Most recurrence pattern was DM (85\%). Ten (4.5\%) elderly patients had contralateral BC. At the last follow-up, 35 (8.5\%) patients died from $\mathrm{BC}$, and 60 (16.5\%) patients died from other causes not related to BC. The recurrence patterns and survival status of the patients are shown in Table 4 .

\section{Discussion}

Several prognostic factors have been identified in the literature for recurrences or death from BC. The strongest prognostic factors are age at diagnosis, co-morbidity, tumor size, histological grade, and number of involved lymph nodes.[28,29] Some studies showed that the risk of $\mathrm{BC}$ recurrence is higher in the younger age. In five NSABP trials among 10,709 women, the 12-year incidence of ipsilateral breast tumor recurrences for women aged 49 years or younger, $50-59$ years, and 60 years or older were $9.6 \%, 5.8 \%$, and 5.6\%, respectively.[28] Rudra et al examined the recurrence patterns in patients with BC. Women aged less than 40 years had higher rates of LRR ( $20 \%$ vs. $7, \mathrm{p}=0.004)$ and $\mathrm{DR}(18 \%$ vs. $5 \%, \mathrm{p}=0.003)$ compared to patients aged above 70 years.[30] Although young age at diagnosis was shown to be associated with an increased risk of recurrence and poorer survival $[3,8,25]$, the exact reason for this poor prognosis 
Table 3 Multi-variant analyses of disease free survival, breast cancer specific survival and overall survival

\begin{tabular}{|c|c|c|c|c|}
\hline Variable & Parameter & HR & $95 \% \mathrm{Cl}$ & $\mathbf{p}$ \\
\hline \multicolumn{5}{|c|}{ Locoregional recurrence-free survival } \\
\hline Age & $\leq 35$ vs $\geq 70$ & 1.12 & $0.30-4.14$ & 0.868 \\
\hline Surgery & MRM vs BCS & 0.13 & $0.04-0.46$ & 0.002 \\
\hline Clinical stage & III+II vs I & 2.41 & $0.71-8.14$ & 0.155 \\
\hline Pathologic tumor stage & T3-4 vs T0-2 & 4.17 & $1.21-13.55$ & 0.018 \\
\hline Pathologic node status & N1-3 vs N0 & 1.24 & $0.28-5.39$ & 0.771 \\
\hline Grade & III vs I+II & 3.67 & $1.13-11.4$ & 0.030 \\
\hline LVSI & Positive vs negative & 5.39 & $1.12-26.1$ & 0.036 \\
\hline $\mathrm{HR}$ & Positive vs negative & 0.47 & $0.18-12.31$ & 0.653 \\
\hline HER2 & Positive vs negative & 0.94 & $0.21-4.28$ & 0.940 \\
\hline Endocrine therapy & Yes vs No & 2.28 & $0.087-59.6$ & 0.620 \\
\hline Adjuvant chemotherapy & Yes vs No & 0.64 & $0.062-6.81$ & 0.718 \\
\hline Trastuzumab & Yes vs No & 0.16 & $0.034-0.75$ & 0.020 \\
\hline \multicolumn{5}{|l|}{ Distant recurrence-free survival } \\
\hline Age & $\leq 35$ vs $\geq 70$ & 1.73 & $1.04-2.89$ & 0.034 \\
\hline Surgery & MRM vs BCS & 0.96 & $0.59-1.55$ & 0.863 \\
\hline Clinical stage & III+II vs I & 1.41 & $0.88-2.23$ & 0.156 \\
\hline Pathologic tumor stage & T3-4 vs T0-2 & 1.89 & $1.21-2.96$ & 0.006 \\
\hline Pathologic node status & N1-3 vs N0 & 2.21 & $1.16-4.16$ & 0.015 \\
\hline Grade & III vs I+II & 1.36 & $0.88-2.09$ & 0.164 \\
\hline LVSI & Positive vs negative & 1.52 & $0.94-2.47$ & 0.090 \\
\hline $\mathrm{HR}$ & Positive vs negative & 0.57 & $0.18-1.86$ & 0.357 \\
\hline HER2 & Positive vs negative & 0.65 & $0.35-1.22$ & 0.179 \\
\hline Endocrine therapy & Yes vs No & 1.47 & $0.46-4.69$ & 0.515 \\
\hline Adjuvant chemotherapy & Yes vs No & 1.06 & $0.42-2.67$ & 0.892 \\
\hline Trastuzumab & Yes vs No & 0.59 & $0.28-1.22$ & 0.175 \\
\hline \multicolumn{5}{|l|}{ Breast cancer specific survival } \\
\hline Age & $\leq 35$ vs $\geq 70$ & 0.96 & $0.56-1.76$ & 0.897 \\
\hline Surgery & MRM vs BCS & 0.99 & $0.54-1.82$ & 0.993 \\
\hline Clinical stage & III+II vs I & 1.78 & $1.02-3.10$ & 0.041 \\
\hline Pathologic tumor stage & T3-4 vs T0-2 & 1.76 & $1.02-3.05$ & 0.042 \\
\hline Pathologic node status & N1-3 vs N0 & 2.49 & $1.08-5.75$ & 0.032 \\
\hline Grade & III vs I+II & 2.29 & $1.34-3.93$ & 0.003 \\
\hline LVSI & Positive vs negative & 1.11 & $0.62-1.98$ & 0.714 \\
\hline $\mathrm{HR}$ & Positive vs negative & 0.35 & $0.07-1.63$ & 0.181 \\
\hline HER2 & Positive vs negative & 0.77 & $0.38-1.56$ & 0.478 \\
\hline Endocrine therapy & Yes vs No & 2.52 & $0.53-11.8$ & 0.240 \\
\hline Adjuvant chemotherapy & Yes vs No & 1.16 & $0.45-5.70$ & 0.456 \\
\hline Trastuzumab & Yes vs No & 0.89 & $0.37-2.14$ & 0.798 \\
\hline \multicolumn{5}{|l|}{ Overall survival } \\
\hline Age & $\leq 35$ vs $\geq 70$ & 0.43 & $0.26-0.69$ & 0.001 \\
\hline Surgery & MRM vs BCS & 0.96 & $0.58-1.58$ & 0.879 \\
\hline Clinical stage & III+II vs I & 1.72 & $1.07-2.74$ & 0.024 \\
\hline Pathologic tumor stage & T3-4 vs T0-2 & 1.56 & $0.99-2.45$ & 0.053 \\
\hline Pathologic node status & N1-3 vs NO & 1.67 & $0.91-3.05$ & 0.094 \\
\hline Grade & III vs I+II & 2.19 & $1.43-3.37$ & 0.001 \\
\hline LVSI & Positive vs negative & 1.13 & $0.71-1.79$ & 0.597 \\
\hline $\mathrm{HR}$ & Positive vs negative & 0.29 & $0.08-1.04$ & 0.057 \\
\hline HER2 & Positive vs negative & 0.98 & $0.56-1.71$ & 0.942 \\
\hline Endocrine therapy & Yes vs No & 3.27 & $0.92-11.6$ & 0.066 \\
\hline Adjuvant chemotherapy & Yes vs No & 0.82 & $0.42-1.58$ & 0.554 \\
\hline Trastuzumab & Yes vs No & 1.39 & $0.64-3.07$ & 0.403 \\
\hline
\end{tabular}

CI: Confidence interval; MRM: Modified radical mastectomy; BCS: Breast-conserving surgery; In: Lymph node; ECE: Extracapsular extension;

LVSI: Lymphovascular space invasion; HR: Hormone receptor 
Table 4 The recurrence patterns and survival status of the patients

Young women $\mathrm{n}$, (\%)

$277(74 \%)$

$98(26 \%)$

$6(6 \%)$

$84(86 \%)$

$8(8 \%)$

Local-regional+distant

Survival status

Alive

Exitus from breast cancer

Exitus from other causes

$319(84 \%)$

55 (15\%)

$4(1 \%)$
Elderly women n, (\%)

$310(87 \%)$

46 (13\%)

$3(6 \%)$

$39(85 \%)$

4 (9\%)

$272(75 \%)$

$31(8.5 \%)$

60 (16.5)

p
0.0001

0.98

0.0001 a

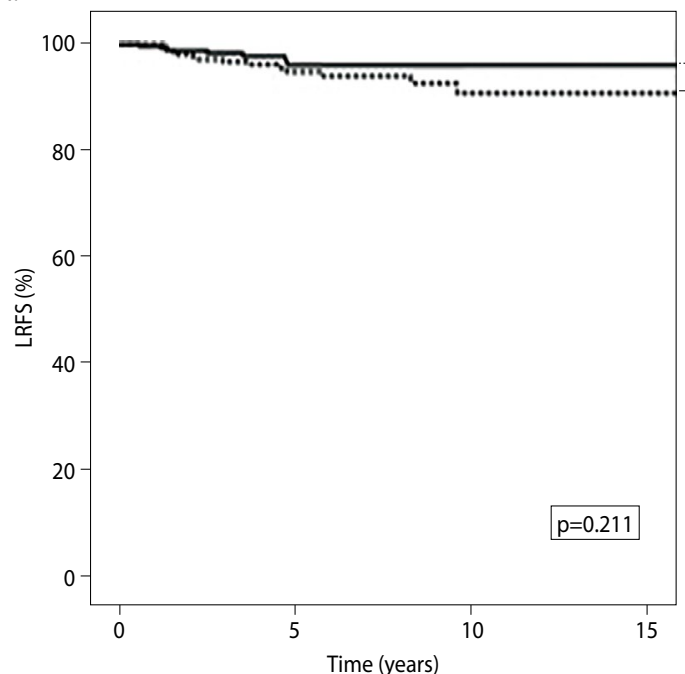

c

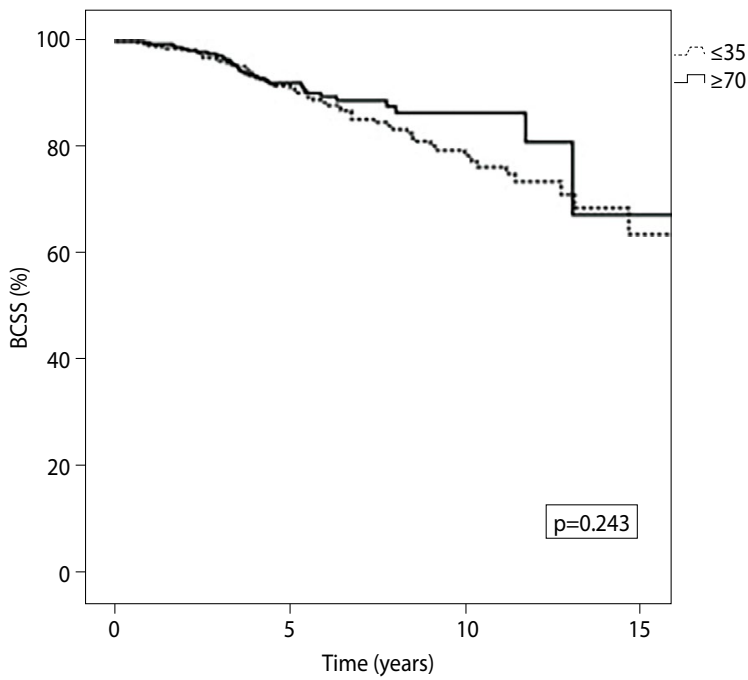

b

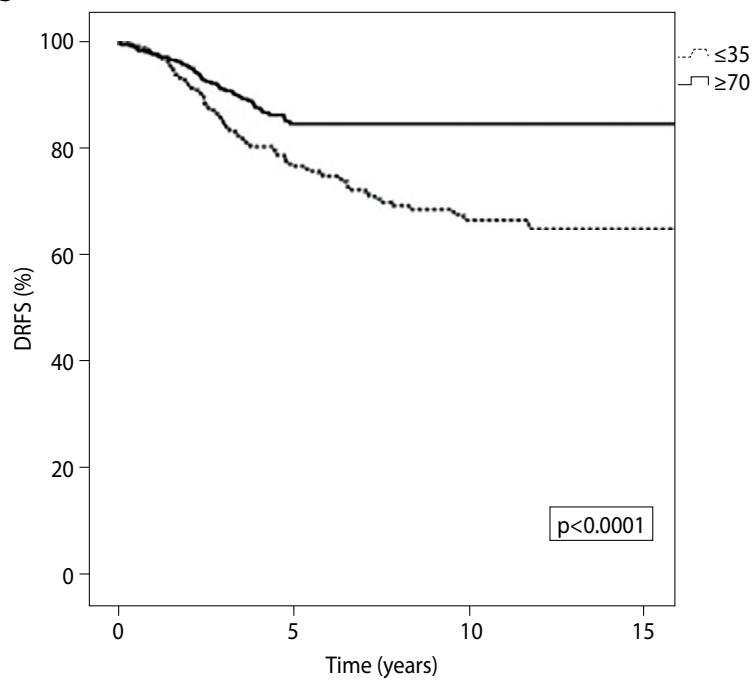

d

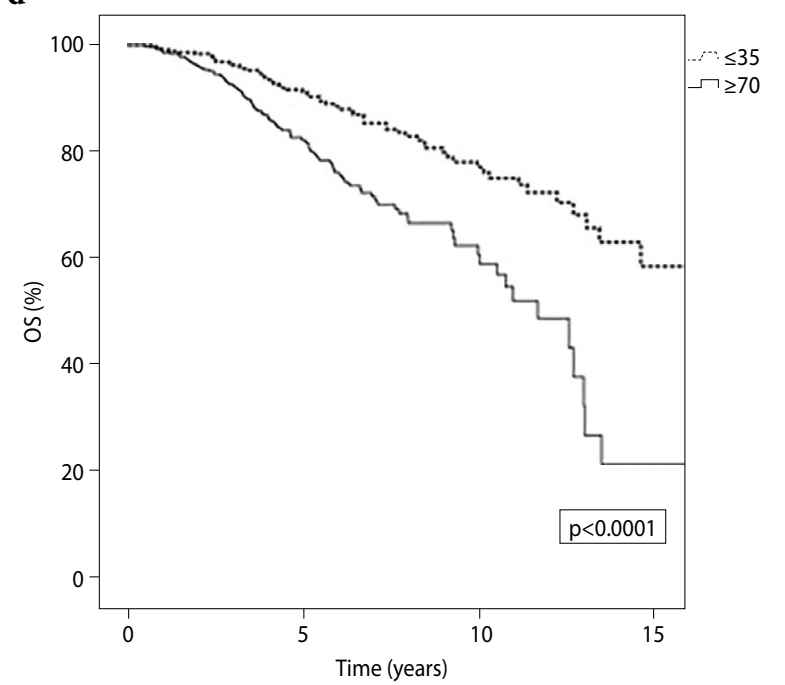

Fig. 1. The LRFS (a), DRFS (b), BCSS (c), and OS (d) of very young women and elderly women diagnosed with breast cancer. 
remains unclear. Numerous publications revealed that the adverse tumor features at young age are related to poor outcome. Similar to previous reports $[5,7,8,10,12]$, our study showed that the BC in young patients younger than $\leq 35$ years is characterized by a higher frequency of aggressive pathological features.

These unfavorable tumor characteristics and the disparity in treatment approaches might contribute to higher recurrence rates in younger patients. We found that the young patients were two times more likely to have recurrence rate than elderly. However, the recurrence patterns did not differ between the groups. The recurrences were mostly appeared in DR. The 5- and 10-year cumulative incidence of DR were significantly higher in the young patients, justifying more intensive chemotherapy following surgery in these age groups of patients. The St Gallen 1998 consensus identified diagnosis at 35 years or younger as a poor prognostic factor, and they recommended adjuvant chemotherapy regardless of tumor features.[31] However, this recommendation was not based on strong evidence. Now, the systemic chemotherapy decision is predominantly based on not only patient age but also patients' comorbidities and performance status and tumor stage and other clinical and molecular prognostic factors. In literature, it has been shown that elderly patients less likely received chemotherapy for their BC [32], and when they received chemotherapy, most of them were treated with non-cardiotoxic agents. [33] Similar to numerous reports [34-36], our study revealed that the number of young patients whom received chemotherapy was higher than elderly, and they mostly received neoadjuvant chemotherapy because of higher incidence of advanced clinical stage. Their chemotherapy regimens contained mainly anthracycline and taxane. The incidence of HER2 positivity in young patients was significantly higher compared to the elderly, but there was no significant difference in terms of anti-HER2 treatment in both groups. The reason for this may be the nature of the retrospective study with unbalanced data set or because most of our patients were treated before anti-HER2 treatment era. Therefore, no conclusion can be drawn for the contributing effect of this agent to improve distant metastasis control.

The 5- and 10-year cumulative incidences of LRR were not found significantly different between the groups, though young patients had significantly more adverse tumor features and significantly higher clinical and pathological stage of the disease. The reason for the similarity between the age groups in terms of LRR might be that the young patients received more comprehensive lymphatic irradiation and tumor bed boost that has been shown to reduce LRR.[37] On the other hand, we found that the LRR in our series was quite lower compared to older series. Beadle et al reported a 10 -year LRR rate of $16 \%$ after breast-conserving therapy and $12.5 \%$ after mastectomy in a cohort of 652 women aged 35 years or younger.[4] Voogd et al reported 10-year LRR rate of $35 \%$ after breast-conserving therapy in women aged 35 years or younger.[38] Patients with $\leq 35$ years of age in our series showed $6 \%$ isolated locoregional recurrence and $8 \%$ LRR and DR with a median follow-up time of 67.5 months. In more recent series, the 5- and 10-year cumulative incidences of LRR were $1 \%$ and $4 \%$ after breast-conserving therapy; $3.5 \%$ and $8.7 \%$ after mastectomy in women aged 40 years or younger, which was quite similar to our results.[39]

Historically, young patients had worse survival than older counterparts. Cancello et al reported that for the patients aged $<35$ years, the risk of death rose by $5 \%$ for every 1-year reduction in age, whereas there was no significant change in death risk with age in patients aged 35-50 years.[16] It is speculated that younger age have a higher risk of death compared to older counterparts even if they are diagnosed early and receive more intensive treatment.[8] Prognosis in BC has dramatically improved over the past decades. According to 2017 data from the American Cancer Society, overall BC death rates increased by $0.4 \%$ per year from 1975 to 1989 , but since then the death rates have decreased rapidly, for a total decline of $39 \%$ through 2015 . This decrease after 1989 occurred in both younger and older women. [40] The differences related to age may be narrowing as the treatment of patients with $\mathrm{BC}$ improves. The better preoperative staging, margin assessment, new systemic agents, and modern radiotherapy techniques may contribute better local-regional control and survival.[39] In one of the recent studies, no significant difference in 5 -year survival was found between the patients aged 35 years or younger and the patients aged 65 years or older in despite of lower 5-year RFS in patients with young age.[27] Similar to this study, we found no significant difference in terms of BCSS between the groups though the difference in 10 -year BCSS rate was $8 \%$. This can be explained by more intensive treatments that young patients have received because of better performance status and tolerability, which compensate the negative impact of young age on BCSS.

It is not surprising to find that the 5- and 10-year OS rates were significantly lower in the elderly. Since these women had more likely to have co-morbidities and many of them died because of other reasons than that of BC.

The strengths of our study can be summarized as having two distinct age groups, which were underrepresented populations and fall out of screening programs. 
The patient data were reviewed in terms of pathological features and treatment approaches as well as recurrence patterns and survival. In contrast to most studies in literature, the treatment and recurrence patterns were represented in detail. However, several limitations should also be mentioned. First, the nature of the retrospective study made unbalanced data set, and some lost information of patients and treatment characteristics was inevitable. Second, there is a selection bias in terms of treatment, since all patients received radiotherapy, and we do not know the consequence of patients without RT.

\section{Conclusion}

In conclusion, similar to previous reports, we have demonstrated that the younger patients had more aggressive pathological features and advanced stage. The LRFS between two distinct age groups was found similar in spite of the presence of adverse tumor features. The reason of this can be explained by more comprehensive lymphatic irradiation and tumor bed boost that the young patients received, justifying more aggressive $\mathrm{RT}$ in this age groups of patients. The DRFS rates were significantly lower in the young patients even though they received more intensive chemotherapy. Future studies are needed for more effective systemic regimens to decrease DR in young patients.

Peer-review: Externally peer-reviewed.

Conflict of Interest: There is no conflict of interest.

Ethics Committee Approval: The local ethics committee approved the study.

Financial Support: There is no financial sport.

Authorship contributions: Concept - Ö.P.E., C.Ö.; Design - Ö.P.E., F.Y., M.G., C.Ö.; Supervision - Ö.P.E.; Materials Ö.P.E., S.Y.S., Ş.A.E., B.A., B.A., M.G., D.Ç.Ö., Z.A., C.Ö., B.G., M.A., G.Ö., İ.B.G., F.Y.; Data collection \&/or processing - Ö.P.E., S.Y.S., Ş.A.E., B.A., B.A., M.G., D.Ç.Ö., Z.A., C.Ö., B.G., M.A., G.Ö., İ.B.G., F.Y.; Analysis and/or interpretation - Ö.P.E., F.Y.; Literature search - Ö.P.E., M.G.; Writing Ö.P.E., M.G.; Critical review - Ö.P.E., F.Y., M.G., C.Ö.

\section{References}

1. Jemal A, Bray F, Center MM, Ferlay J, Ward E, Forman D. Global cancer statistics. CA Cancer J Clin 2011;61(2):69-90.

2. Howlader N, Noone AM, Krapcho M, Miller D, Bishop K, Kosary CL, et al. SEER Cancer Statistics Review. 1975-2014. Available at: https://seer.cancer.gov/ csr/1975_2014/. Accessed, April 2017. Bethesda, MD: National Cancer Institute, 2017.
3. Chung M, Chang HR, Bland KI, Wanebo HJ. Younger women with breast carcinoma have a poorer prognosis than older women. Cancer 1996;77(1):97-103.

4. Beadle BM, Woodward WA, Tucker SL, Outlaw ED, Allen PK, Oh JL, et al. Ten year recurrence rates in young women with breast cancer by locoregional treatment approach. Int J Radiat Oncol Biol Phys 2009;73(3):734-44.

5. Anders CK, Hsu DS, Broadwater G, Acharya CR, Foekens JA, Zhang Y, et al. Young age at diagnosis correlates with worse prognosis and defines a subset of breast cancers with shared patterns of gene expression. J Clin Oncol 2008;26(20):3324-30.

6. Singh R, Hellman S, Heimann R. The natural history of breast carcinoma in the elderly: implications for screening and treatment. Cancer 2004;100(9):1807-13.

7. Copson E, Eccles B, Maishman T, Gerty S, Stanton L, Cutress RI, et al. Prospective observational study of breast cancer treatment outcomes for UK women aged 18-40 years at diagnosis: the POSH study. J Natl Cancer Inst 2013;105(13):978-88.

8. Fredholm H, Eaker S, Frisell J, Holmberg L, Fredriksson I, Lindman H. Breast cancer in young women: poor survival despite intensive treatment. PLoS One 2009;4(11):7695.

9. Grumpelt AM, Ignatov A, Tchaikovski SN, Burger E, Costa SD, Eggemann H. Tumor characteristics and therapy of elderly patients with breast cancer. J Cancer Res Clin Oncol 2016;142(5):1109-16.

10. Nixon AJ, Neuberg D, Hayes DF, Gelman R, Connolly JL, Schnitt S, et al. Relationship of patient age to pathologic features of the tumor and prognosis for patients with stage I or II breast cancer. J Clin Oncol 1994;12(5):888-94.

11. Kurtz JM, Jacquemier J, Amalric R, Brandone $\mathrm{H}$, Ayme Y, Hans D, et al. Why are local recurrences after breast-conserving therapy more frequent in younger patients? J Clin Oncol 1990;8(4):591-8.

12. de Kruijf EM, Bastiaannet E, Rubertá F, de Craen AJ, Kuppen PJ, Smit VT, van de Velde CJ, Liefers GJ. Comparison of frequencies and prognostic effect of molecular subtypes between young and elderly breast cancer patients. Mol Oncol 2014;8(5):1014-25.

13. Anders CK, Fan C, Parker JS, Carey LA, Blackwell KL, Klauber-DeMore N, et al. Breast carcinomas arising at a young age: unique biology or a surrogate for aggressive intrinsic subtypes? J Clin Oncol 2011;29(1):18-20.

14. Colleoni M, Rotmensz N, Robertson C, Orlando L, Viale $G$, Renne $G$, et al. Very young women ( $<35$ years) with operable breast cancer: features of diseaseat presentation. Ann Oncol 2002;13(2):273-9.

15. Kheirelseid EH, Boggs JM, Curran C, Glynn RW, Dooley C, Sweeney KJ, et al. Younger age as a prognostic indicator in breast cancer: a cohort study. BMC Cancer 2011;11:383. 
16. Cancello G, Maisonneuve P, Rotmensz N, Viale G, Mastropasqua MG, Pruneri G, et al. Prognosis and adjuvant treatment effects in selected breast cancer subtypes of very young women ( $<35$ years) with operable breast cancer. Ann Oncol 2010; 21(10):1974-81.

17. Ferlay J, Shin HR, Bray F, Forman D, Mathers C, Parkin DM. Estimates of worldwide burden of cancer in 2008: GLOBOCAN 2008. Int J Cancer 2010;127(12):2893-917.

18. Axelrod D, Smith J, Kornreich D, Grinstead E, Singh $\mathrm{B}$, Cangiarella J, et al. Breast cancer in young women. J Am Coll Surg 2008;206(6):1193-203.

19. Pierga JY, Girre V, Laurence V, Asselain B, Diéras V, Jouve M, et al. Characteristics and outcome of 1755 operable breast cancers in women over 70 years of age. Breast 2004;13(5):369-75.

20. Gennari R, Curigliano G, Rotmensz N, Robertson C, Colleoni M, Zurrida S, et al. Breast carcinoma in elderly women: features of disease presentation, choice of local and systemic treatments compared with younger postmenopasual patients. Cancer 2004;101(6):1302-10.

21. Laird-Fick HS, Gardiner JC, Tokala H, Patel P, Wei S, Dimitrov NV. HER2 status in elderly women with breast cancer. J Geriatr Oncol 2013;4(4):362-7.

22. Diab SG, Elledge RM, Clark GM. Tumor characteristics and clinical outcome of elderly women with breast cancer. J Natl Cancer Inst 2000;92(7):550-6.

23. Bergman L, Kluck HM, van Leeuwen FE, Crommelin MA, Dekker G, Hart AA, et al. The influence of age on treatment choice and survival of elderly breast cancer patients in south-eastern Netherlands: a populationbased study. Eur J Cancer 1992;28(8-9):1475-80.

24. Greer LT, Rosman M, Charles Mylander W, Liang W, Buras RR, Chagpar AB, et al. A prediction model for the presence of axillary lymph node involvement in women with invasive breast cancer: a focus on older women. Breast J 2014;20(2):147-53.

25. Hamaker ME, Bastiaannet E, Evers D, Water Wv, Smorenburg $\mathrm{CH}$, Maartense E, et al. Omission of surgery in elderly patients with early stage breast cancer. Eur J Cancer 2013;49(3):545-52.

26. Gajdos C1, Tartter PI, Bleiweiss IJ, Lopchinsky RA, Bernstein JL. The consequence of undertreating breast cancer in the elderly. J Am Coll Surg 2001;192:698-707.

27. Wang J, Wang J, Li Q, Zhang P, Yuan P, Ma F, Luo Y, et al. Young breast cancer patients who develop distant metastasis after surgery have better survival outcomes compared with elderly counterparts. Oncotarget 2017;8(27):44851-9.

28. Greene FL, Page DL, Fleming ID, Fritz AG, Balch CM, Haller DG, Morrow M, editors. AJCC cancer staging manual. 6th ed. New York: Springer, 2002.
29. Wallgren A, Bonetti M, Gelber RD, Goldhirsch A, Castiglione-Gertsch M, Holmberg SB, et al. Risk factors for locoregional recurrence among breast cancer patients: results from International Breast Cancer Study Group Trials I through VII. J Clin Oncol 2003;21(7):1205-13.

30. Rudra S, Yu DS, Yu ES, Switchenko JM, Mister D, Torres MA. Locoregional and distant recurrence patterns in young versus elderly women treated for breast cancer. Int J Breast Cancer 2015;2015:213123.

31. Goldhirsch A, Glick JH, Gelber RD, Senn HJ. International Consensus Panel on the treatment of primary breast cancer. V: Update 1998. Recent Results Cancer Res 1998;152:481-97.

32. Brunello A, Basso U, Pogliani C, Jirillo A, Ghiotto C, Koussis $\mathrm{H}$, et al. Adjuvant chemotherapy for elderly patients ( $>$ or $=70$ years) with early high-risk breast cancer: a retrospective analysis of 260 patients. Ann Oncol 2005;16(8):1276-82.

33. Giordano SH, Hortobagyi GN, Kau SW, Theriault RL, Bondy ML. Breast cancer treatment guidelines in older women. J Clin Oncol 2005;23(4):783-91.

34. Mustacchi G, Cazzaniga ME, Pronzato P, De Matteis A, Di Costanzo F, Floriani I; NORA Study Group. Breast cancer in elderly women: a different reality? Results from the NORA study. Ann Oncol 2007;18(6):991-6.

35. Bastiaannet E, Portielje JE, van de Velde CJ, de Craen AJ, van der Velde S, Kuppen PJ, et al. Lack of survival gain for elderly women with breast cancer. Oncologist 2011;16(4):415-23.

36. Enger SM, Thwin SS, Buist DS, Field T, Frost F, Geiger AM, et al. Breast cancer treatment of older women in integrated health care settings. J Clin Oncol 2006;24(27):4377-83.

37. Bartelink H, Maingon P, Poortmans P, Weltens C, Fourquet A, Jager J, et al. Whole-breast irradiation with or without a boost for patients treated with breast-conserving surgery for early breast cancer: 20 year follow-up of a randomised phase 3 trial. Lancet Oncol 2015;16(1):47-56.

38. Voogd AC, Nielsen M, Peterse JL, Blichert-Toft M, Bartelink $H$, Overgaard $M$, et al. Differences in risk factors for local and distant recurrence after breastconserving therapy or mastectomy for stage I and II breast cancer: pooled results of two large European randomized trials. J Clin Oncol 2001;19(6):1688-97.

39. Plichta JK, Rai U, Tang R, Coopey SB, Buckley JM, Gadd MA, et al. Factors Associated with Recurrence Rates and Long-Term Survival in Women Diagnosed with Breast Cancer Ages 40 and Younger. Ann Surg Oncol 2016;23(10):3212-20.

40. American Cancer Society. Breast Cancer Facts\&Figures 2017-2018. Atlanta: American Cancer Society, Inc. 2017. 